\title{
EL PRINCIPIO DE COMPLEMENTARIEDAD EN LA INVESTIGACIÓN, JUZGAMIENTO Y SANCIÓN DE DELITOS INTERNACIONALES *
}

\section{The principle of complementarity in the investigation, judgment and punishment of international crimes}

\author{
Alfonso Daza González** \\ Universidad Católica de Colombia. Bogotá, D.C.
}

Recepción: 11 de febrero de 2016. Aceptación: 30 de mayo de 2016.

DOI: http://dx.doi.org/10.21017/Rev.Repub.2016.v21.a11

\section{RESUMEN}

En este artículo se analiza la existencia de tensiones procesales entre los tribunales penales nacionales -jurisdicción nacional-, la jurisdicción universal y jurisdicción de la Corte Penal Internacional, o si por el contrario estos sistemas procesales penales se complementan frente a la aplicación de la ley penal en torno a la investigación, juzgamiento y sanción de los crímenes más graves de trascendencia para la comunidad internacional en su conjunto. El problema que se plantea es el siguiente: ¿Existen tensiones procesales entre los tribunales penales nacionales jurisdicción nacional y jurisdicción universal y la Corte Penal Internacional, o si estos sistemas procesales penales se complementan frente a la aplicación de la ley penal en torno a la investigación, juzgamiento y sanción de los crímenes más graves de trascendencia para la comunidad internacional en su conjunto? La tesis que se defiende es que entre la jurisdicción de los Tribunales Nacionales, en la que se desarrolla tanto la jurisdicción nacional como la jurisdicción universal, y la jurisdicción de la Corte Penal Internacional, no existen tensiones, sino que estas se complementan.

\footnotetext{
* Artículo producto de la investigación adelantada por el autor en la Facultad de Derecho de la Universidad Católica de Colombia, titulada El principio de complementariedad.

** Doctor en Derecho de la Universidad Externado de Colombia. Doctor en Derecho de la Universidad Alfonso X El Sabio (Madrid, España). Máster en Derechos Humanos, Estado de Derecho y Democracia en Iberoamerica de la Universidad Alcalá de Henares (España). Abogado de la Universidad Libre, especialista y magíster en Derecho Penal y Criminología de la misma Universidad. Docente de las universidades Libre y Católica de Colombia. Correo electrónico: adazaabogado@hotmail.com
} 

juzgamiento y sanción de delitos internacionales

Palabras clave: Investigación, juzgamiento, sanción, crímenes internacionales, Jurisdicción nacional, jurisdicción universal, Corte Penal Internacional, principio de complementariedad.

\begin{abstract}
This article discusses the existence of procedural tensions between national criminal courts - national jurisdiction-, universal jurisdiction and the international criminal court jurisdiction, or if on the contrary these criminal procedural systems complement each other against the application of the criminal law on investigation, prosecution and punishment of the most serious crimes of concern to the entire international community. The problem that arises, it relies on the following: Do Procedural tensions among national or international criminal tribunals exist or these systems complemented each other? Our thesis for this question sustains that National and International Criminal Courts jurisdictions dovetail with each other rather than create tensions.
\end{abstract}

Key wordos: Investigation, judgement, punishment, international crimes, national jurisdiction, universal jurisdiction, International Criminal Court, principle of complementarity.

\title{
PROBLEMA JURÍDICO
}

El problema jurídico que se plantea en esta investigación es el siguiente: ¿Existen tensiones procesales entre los tribunales penales nacionales jurisdicción nacional y jurisdicción universal y la Corte Penal Internacional o estos sistemas procesales penales se complementan frente a la aplicación de la ley penal en torno a la investigación, juzgamiento y sanción de los crímenes más graves de trascendencia para la comunidad internacional en su conjunto $^{1}$ ?

$\mathrm{Al}$ respecto, y esa es nuestra tesis, debemos señalar que entre estos sistemas procesales penales no existe ninguna tensión. Lejos de ella, en materia de investigación, juzgamiento y sanción de los crímenes más graves de trascen-

1 Así define el ESTATUTO DE LA CORTE PENAL INTERNACIONAL en el artículo $5 .^{\circ}$ los crímenes de genocidio, lesa humanidad, guerra y agresión. Adoptado por la Conferencia Diplomática de Plenipotenciarios de las Naciones Unidas, Roma, el 17 de julio de 
dencia para la comunidad internacional en su conjunto, estos sistemas procesales penales, se complementan.

\section{METODOLOGÍA UTILIZADA}

Se trata de una investigación básica jurídica, porque el objeto de estudio lo constituye la norma jurídica: los aspectos generales de jurisdicción. La jurisdicción nacional: deberes de los Estados de investigar, juzgar y sancionar los delitos internacionales; la jurisdicción universal, donde se destacan la diversas fuentes que la conceptualizan, como ciertas convenciones, normas de Soft Law, casos jurisprudenciales y doctrina; principios del derecho penal internacional que orientaron formación y resoluciones de los tribunales internacionales y del Estatuto de Roma.

Se combinarán fuentes secundarias y terciarias. En cuanto a las secundarias, se analizarán normas nacionales, instrumentos internacionales de derecho penal internacional, relacionados con el eje problemático propuesto; y en relación con las fuentes terciarias, analizaremos las fuentes obtenidas o utilizadas por otros autores.

\section{OBJETIVO GENERAL}

Determinar si entre la jurisdicción de los Tribunales Nacionales, en la que se desarrolla tanto la jurisdicción nacional como la jurisdicción universal, y la jurisdicción de la Corte Penal Internacional, existen tensiones o si, por el contrario, estas se complementan.

\section{RESULTADOS OBTENIDOS}

Observadas las diversas posibilidades que tienen los Estados para ejercer su jurisdicción, amparada en múltiples fuentes y principios, cabe preguntarse cómo podrían resolverse eventuales conflictos de jurisdicción, particularmente respecto de los delitos internacionales, es decir, respecto de aquellos hechos o crímenes cuyo conocimiento y juzgamiento pudiera corresponder tanto al

1998. Incisos 3..$^{\circ}$ y . $^{\circ}$ del artículo 93 de la Constitución Política de 1991, adicionados por el artículo 1. ${ }^{\circ}$ del Acto Legislativo nro. 2 de 2001 publicado en el Diario Oficial nro. 44.663, de 31 de diciembre de 2001. 
El principio de complementariedad en la investigación, juzgamiento y sanción de delitos internacionales

tribunal internacional como al doméstico ${ }^{2}$. Relación que se regulaba en términos generales por dos tipos de regímenes: el de competencia exclusiva y el de competencia concurrente . $^{3}$.

Si bien este conflicto ha sido superado dentro de la jurisdicción de la Corte Penal Internacional, tal como fue mencionado al describir el principio de la complementariedad, el Estatuto de Roma adopta este principio para prevenir y regular los conflictos de jurisdicción y competencia entre la Corte y los tribunales domésticos; estableciéndola como una figura esencial de la admisibilidad, de los mecanismos de inicio de procedimientos. Impidiendo cualquier situación de conflicto de competencias, y salvaguardando además los mecanismos de cooperación que los Estados partes deben implementar para dar eficiencia a las labores y decisiones de la Corte.

El debate permanece vigente, especialmente respecto de la jurisdicción universal como mencionamos oportunamente; por ello resultan especialmente clarificadoras ciertas consideraciones respecto de los tribunales internacionales.

Es especial el régimen de competencia adoptado por los Tribunales Militares Internacionales de Nuremberg y Tokio. El primero de ellos, por ejemplo, tenía competencia exclusiva para juzgar a los «mayores criminales de guerra alemanes», cuyos crímenes no tuvieron una localización geográfica particular ${ }^{4}$.

Mientras que el régimen de competencias concurrentes consiste en otorgar competencia tanto al tribunal internacional como al doméstico, existiendo dos modelos de solución frente a los eventuales conflictos: conceder la preeminencia a las cortes internacionales o a las nacionales ${ }^{5}$. Esa es la fómula adoptada por los Tribunales Penales Internacionales posteriores a Núremberg y Tokyo en las diferentes modalidades descritas atrás (tribunales internacionales e híbridos), los cuales han recogido el principio de competencia concurrente, y han agregado la primacía del tribunal especial para conocer de los casos de acuerdo con los criterios que considere pertinentes en cualquier etapa de los

2 SEGOVIA, Antonio, Contreras, Marcelo. El principio de complementariedad y el ejercicio de la competencia en el Estatuto de Roma. Una visión crítica. En: La Corte Penal Internacional y sus primeros 10 Años: Un enfoque práctico, Santiago de Chile, Thomson Reuters, 2013, pp. 265-302

3 WERLE, Gerhard. El principio de complementariedad: una mirada retrospectiva y prospectiva, En: Corte Penal Internacional y jurisdicciones estatales. El principio de complementariedad, Santiago, Legal Publishing Chile, pp. 71-88.

4 Véase preámbulo y art. $1 .^{\circ}$ del Acuerdo de Londres, de 1945 y art. $6 .^{\circ}$ del Estatuto del Tribunal Militar Internacional

5 SEGOVIA, Antonio, Contreras, Marcelo. Op. cit. pp. 271-272. 
procesos. A esta fórmula hay que agregar la innovación que hiciera el Tribunal Penal Internacional de Yugoeslavía al establecer la Regla 11bis en las Reglas de Procedimiento Prueba, de acuerdo con la cual, como parte de la estrategia de conclusión, puede por iniciativa propia remitir casos a los tribunales o cortes nacionales, igualmente, en cualquier etapa del proceso.

\section{INTRODUCCIÓN}

La complementariedad es el mecanismo jurídico mediante el cual se plasma la interacción de la Corte Penal Internacional con las jurisdicciones nacionales ${ }^{6}$. Consagrado bajo la figura de cuestiones de admisibilidad, este principio constituye la piedra angular de las relaciones entre la Corte y las jurisdicciones locales para la implementación de las obligaciones de investigar y enjuiciar a los responsables de crímenes internacionales, que el artículo 86 del Estatuto le impone a los Estados ${ }^{7}$.

Así, este principio evita la existencia de conflictos de competencia entre la Corte y los Estados, al ubicar preferentemente la obligación erga omnes de investigar, perseguir y castigar a los responsables de crímenes internacionales en las jurisdicciones nacionales, la que además debe desarrollarse dentro de ciertos marcos de eficiencia y efectividad. Por ello es que también se considera que la Corte constituye un poderoso incentivo para que los tribunales nacionales instruyan procedimientos en contra las personas sospechosas de participar en crímenes internacionales ${ }^{8}$.

El principio de complementariedad surge desde el preámbulo del Estatuto de Roma, donde se establece la obligación de «todo Estado ejercer su jurisdicción penal contra los responsables de crímenes internacionales» y se destaca que la Corte «será complementaria de las jurisdicciones penales nacionales». Adicionalmente, el principio se consagra en los artículos 1 y 17 del Estatuto, en virtud del cual, la Corte solo ejercerá su competencia cuando un asunto determinado en el Estatuto y de cierto umbral de gravedad, no ha sido abordado por las autoridades estatales del o los países competentes o estas no han actuado

6 VALDÉS RIVEROLL, Mariana. El Principio de complementariedad de la Corte Penal Internacional. En: Proyectos legislativos y otros temas penales (Segundas jornadas sobre justicia penal), México D. F.: Universidad Autónoma de México, 2003, pp. 293-299, p. 293.

7 CONTRERAS, Beatriz, Fernández, Karinna. La obligación de cooperar con la Corte Penal Internacional. En: La Corte Penal Internacional y sus primeros 10 años: Un enfoque práctico, Santiago de Chile, Thomson Reuters, 2013, pp. 515-550, p. 520.

8 CASSESE, Antonio. A Big Step Forward for International Justice. En: Crimes of War Magazine, Diciembre, 2003. 
El principio de complementariedad en la investigación, juzgamiento y sanción de delitos internacionales

de acuerdo con los estándares mínimos establecidos en la regulación del Estatuto 9 .

Así, la obligación de investigar y perseguir la responsabilidad de los autores de los crímenes contemplados en el Estatuto corresponde primeramente a los Estados, quienes tienen el deber de ejercer su jurisdicción para la investigación y enjuiciamiento de tales crímenes internacionales.

Por tanto, el principio de complementariedad mantiene la vigencia del sistema preexistente de aplicación indirecta del derecho penal internacional; asegura que los Estados conserven intacta su competencia; 10 facultando a la Corte a actuar, de modo excepcional, en aquellos casos de su competencia cuando los Estados no estén en condiciones o no tengan la voluntad de administrar justicia con el especial objeto de garantizar que los más graves crímenes internacionales no quedarán impunes ${ }^{11}$. De esta forma, el principio de complementariedad garantiza que la jurisdicción de la Corte es de última ratio, es decir, destinada a complementar y no a suplantar las jurisdicciones nacionales.

Corresponde mencionar que es precisamente como consecuencia de este principio que el Estatuto, en su artículo 17.2, permite a la Corte Penal Internacional el ejercicio de jurisdicción incluso cuando los tribunales nacionales hayan juzgado o estén juzgando el mismo caso, cuando sea posible determinar que en dichos procesos no existe una real intención de juzgar a los responsables. ${ }^{12}$ Así, existiendo procesos nacionales en marcha, la Corte actuará únicamente

9 CÁRDENAS ARAVENA, Claudia. La Cooperación de los Estados con la Corte Penal Internacional a la luz del Principio de Complementariedad. En: Revista de Derecho de la Pontificia Universidad Católica de Valparaíso, Valparaíso, Pontificia Universidad Católica de Valparaíso, 2010, pp. 281-304. p 284

10 Ibid. P. 283.

11 VALDÉS RIVEROLL, Mariana. Op. cit. p. 297.

12 «Artículo 17 (2). A fin de determinar si hay o no disposición a actuar en un asunto determinado, la Corte examinará, teniendo en cuenta los principios de un proceso con las debidas garantías reconocidos por el derecho internacional, si se da una o varias de las siguientes circunstancias, según el caso: a) Que el juicio ya haya estado o esté en marcha o que la decisión nacional haya sido adoptada con el propósito de sustraer a la persona de que se trate de su responsabilidad penal por crímenes de la competencia de la Corte, según lo dispuesto en el artículo 5; b) Que haya habido una demora injustificada en el juicio que, dadas las circunstancias, sea incompatible con la intención de hacer comparecer a la persona de que se trate ante la justicia; c) Que el proceso no haya sido o no esté siendo sustanciado de manera independiente o imparcial y haya sido o esté siendo sustanciado de forma en que, dadas las circunstancias, sea incompatible con la intención de hacer comparecer a la persona de que se trate ante la justicia». 
cuando los efectos domésticos no sean considerados genuinos a juicio de la Fiscalía de la Corte.

El aspecto práctico de la complementariedad se expresa en la evaluación que debe hacer la oficina de la fiscalía de la Corte para declarar admisible una caso; así el o la fiscal considerará que hay fundamentos razonables para estimar que una situación bajo estudio preliminar es admisible únicamente si en ella se satisfacen los parámetros de complementariedad y gravedad; debiendo, por tanto, verificar que no se esté instruyendo ningún procedimiento doméstico con base en los mismos ilícitos, respecto de los mismos sospechosos, y de existir alguno verificar que el objetivo de dichos procesos es hacer comparecer efectivamente a los responsables ante la justicia. Por tanto, la admisibilidad de un caso «conlleva la presunción de que el Estado en cuestión está actuando en violación de sus obligaciones erga omnes» ${ }^{13}$.

Ahora bien, al margen de las remisiones de situaciones que puede efectuar el Consejo de Seguridad a la Corte, existen otros casos que desde la esfera práctica han generado excepciones a la idea de complementariedad incluida en el Estatuto, a saber, las autorremisiones y la complementariedad positiva.

\section{Las autorremisiones}

Contra la premisa de que los Estados buscan evitar que los crímenes cometidos en su territorio o sus nacionales supuestamente involucrados en hechos criminales sean llevados ante la Corte Penal Internacional, la práctica ha sido predominante en el uso de la figura de las autorremisiones ${ }^{14}$, en virtud de la cual los Estados partes, haciendo uso de la facultad contenida en el artículo 141 del Estatuto ${ }^{15}$, remiten directamente a la Corte una situación de conflicto que tuvo lugar en su propio territorio. La autorremision implica, por tanto, una renuncia o la cesión de su competencia preferente, surgida desde la complementariedad, a la Corte.

13 JESSBERGER, Florian, Geneuss, Julia. Las múltiples caras de la Corte Penal Internacional. En: La Corte Penal Internacional y sus primeros 10 años: Un enfoque práctico, Santiago de Chile, Thomson Reuters, 2013, pp. 199-218, p. 207.

14 De los nueve casos actualmente investigados por la Fiscalía, cuatro han sido autorremisiones (República Democrática del Congo [RDC], Uganda del Norte, la República Centroafricana y Malí); tres remisiones del Consejo de Seguridad de la ONU (Darfur, Sudán y Libia); y dos han sido el resultado de la iniciativa del Fiscal, autorizada por los jueces de la CPI (Kenia y Costa de Marfil).

15 Todo Estado Parte podrá remitir al Fiscal una situación en que parezca haberse cometido uno o varios crímenes de la competencia de la Corte y pedir al Fiscal que investigue la situación a los fines de determinar si se ha de acusar de la comisión de tales crímenes a una o varias personas determinadas. 
El principio de complementariedad en la investigación, juzgamiento y sanción de delitos internacionales

\section{La complementariedad positiva}

La complementariedad positiva es el término utilizado por la oficina de la fiscalía de la Corte Penal ${ }^{16}$ para describir una de sus estrategias destinada a alentar procesos nacionales genuinos de enjuiciamiento de los responsables de situaciones que se encuentran bajo el análisis preliminar de la Fiscalía ${ }^{17}$.

Actualmente la Fiscalía lleva a cabo exámenes preliminares de la situación en Afganistán, Colombia, Georgia, Guinea, Honduras, República de Corea, Malí y Nigeria, en los que basa su decisión de abrir o no una investigación. El examen preliminar es una figura diseñada por la Fiscalía, y que explica en los siguientes términos: «el examen preliminar de la información disponible con respecto a una situación es realizado de manera comprehensiva y detallada. El Fiscal está obligado a continuar con dicho examen hasta el momento en el que la información muestra que existe, o no existe, una base razonable para proceder a la investigación. Por ejemplo, los criterios de complementariedad pueden requerir el monitoreo de ciertos procedimientos nacionales para determinar si los mismos se refieren a los delitos más graves y si son genuinos. En consecuencia, el tiempo y duración de las actividades a desarrollar durante el examen preliminar se tendrán que basar necesariamente en la situación de que se trate» 18

De igual forma, la complementariedad positiva también se aplica a aquellos países respecto de los cuales se hayan abierto investigaciones ${ }^{19}$.

En coherencia con este diseño estratégico, la Fiscalía ha afirmado que el «principio de complementariedad tiene dos dimensiones: i) el test de admisibilidad, o sea, cómo evaluar la existencia de un proceso nacional y su naturaleza genuina, lo cual es un tema judicial; y ii) el concepto de complementariedad positiva o sea una política proactiva de cooperación enfocada en promover procesos nacionales.»20

La Fiscalía se propone bajo esta estrategia, en lugar de declarar directamente la admisibilidad del caso, ayudar a reconstruir y fortalecer el sistema domés-

16 La Fiscalía en sus planes estratégicos 2006-2009 y 2009-2012, incluye los principios sobre los cuales se basa su estrategia: (i) la complementariedad positiva; (ii) investigaciones y prosecuciones enfocadas; iii) los intereses de las víctimas; iv) maximizar el impacto del trabajo de la Fiscalía.

17 En: CPI, Fiscalía, «Borrador de Políticas sobre Exámenes Preliminares», 4 de octubre de 2010 (supra nota 7), párrafo 83.

18 Ibid.

19 Report On The Prosecutorial Strategy (2006), y Prosecutorial Strategy 2009-2012 (2010).

20 Prosecutorial Strategy, 1 de febrero de 2010, p. 4. 
tico de justicia otorgando asistencia y soporte técnicos de manera proactiva, e incentivando a los Estados a cumplir con su responsabilidad preferente de investigar y perseguir.

La complementariedad positiva es objeto de continuo debate, pues no estaba contemplada dentro del Estatuto, porque por muchos es considerada una renuncia a las labores de investigación de la Fiscalía y debido a que su establecimiento impide que la falta de voluntad de los Estados sea debidamente encarada y considerada en relación con los mecanismos suplementarios y negociaciones desarrolladas como parte de la implementación de la misma ${ }^{21}$.

Las críticas más fuertes tienen origen con respecto al caso colombiano que se encuentra en examen desde junio del año $2004,{ }^{22}$ el cual ha sido frecuentemente invocado por la Fiscalía como un ejemplo exitoso de la complementariedad positiva en acción; sostienen que el examen preliminar tan solo significa que la Fiscalía está analizando la situación, lo que implica que sus efectos, aun acompañados de la complementariedad positiva, son en general mínimos y en completa oposición a las repercusiones que pueden generarse con la decisión de abrir una investigación sobre los crímenes internacionales cometidos en el territorio de un Estado parte, evidenciando la gravedad y la seriedad de los mismos y la falta de capacidad o voluntad por parte del Estado de cumplir con sus funciones de investigación y judicialización de los responsables. «Es importante anotar que la apertura de una investigación no es una decisión irreversible, ya que se continuará propugnando por el principio de la complementariedad y profundizando el análisis de la admisibilidad del caso.» ${ }^{23}$

21 FEDERACIÓN INTERNACIONAL DE DERECHOS HUMANOS (FIDH), La CPI, 20022012: 10 años, 10 recomendaciones para una Corte Penal Internacional eficaz e independiente, París, 2012, p. 6.

22 «El 2 de marzo de 2005, el Fiscal informó al Gobierno de Colombia que había recibido información sobre los presuntos crímenes cometidos en Colombia que podrían caer dentro de la jurisdicción de la Corte».

23 ABOGADOS SIN FRONTERAS CANADÁ, CPI y Colombia: Tiempo de actuar en positivo. En: Claudia Cárdenas y Karinna Fernández (eds.), La Corte Penal Internacional y sus primeros 10 años: Un enfoque práctico, Santiago de Chile, Thomson Reuters, 2013, pp. 319359, p. 358. También en ABOGADOS SIN FRONTERAS CANADÁ (2012): «El principio de complementariedad en el Estatuto de Roma y la situación colombiana: más allá de lo positivo. Un análisis sobre la necesidad de adoptar otra aproximación frente a un Estado que no quiere judicializar los crímenes que comprometen su responsabilidad internacional y la de sus altos funcionarios». Disponible en: http:/ / www.asfcanada.ca/ documents/file/asf_rapport-espagnol-v5_lq.pdf 

juzgamiento y sanción de delitos internacionales

\section{Obligaciones de los Estados de cooperar con la Corte Penal Internacional}

El sistema de justicia penal internacional que subyace a la ratificación del Estatuto de Roma debe ser comprendido como un sistema compuesto de dos pilares esenciales: por una parte, la Corte encargada de perseguir y juzgar los casos más graves de crímenes internacionales que no estén siendo o hayan sido adecuadamente investigados o perseguidos por parte de los Estados competentes; «y por otra, los Estados se encargan de ejecutar lo necesario para posibilitar las investigaciones y hacer cumplir lo resuelto por el tribunal. Si alguno de los pilares falla, la estructura en su conjunto falla también.» 24

La relevancia de la referida cooperación estatal se explica en el hecho que el Estatuto fijó las bases orgánicas y estructurales necesarias para el funcionamiento de la Corte. Sin embargo, esta se encuentra desprovista de un aparato propio a través del cual se puedan ejecutar e implementar sus decisiones en el territorio de los Estados ${ }^{25}$.

La sesión IX del Estatuto y las Reglas de Procedimiento y Prueba regula la cooperación internacional y la asistencia judicial entre los Estados y la Corte. En tales instrumentos, la cooperación es concebida como una obligación para los Estados partes de conformidad con sus artículos 86 y $88^{26}$.

Adicionalmente, se encuentra asociada precisamente al principio de complementariedad que rige las relaciones entre los Estados y la Corte, ya que la implementación de las labores de Corte requiere de la contribución y colaboración de los Estados, «como la Corte actúa sobre la base del sistema preexistente (complementa y no reemplaza), forma también parte de la lógica del sistema el hecho de que para poder actuar necesita de la cooperación de los Estados y otros sujetos.» ${ }^{27}$

24 CÁRDENAS ARAVENA, Claudia. La cooperación de los Estados con la Corte Penal Internacional a la luz del Principio de Complementariedad. En: Revista de Derecho de la Pontificia Universidad Católica de Valparaíso, Valparaíso, Pontificia Universidad Católica de Valparaíso, 2010, pp. 281-304. P. 283.

25 CONTRERAS, Beatriz, Fernández, Karinna. Op. cit. p. 522.

26 «Artículo 86: Los Estados Partes, de conformidad con lo dispuesto en el presente Estatuto, cooperarán plenamente con la Corte en relación con la investigación y el enjuiciamiento de crímenes de su competencia; Artículo 88: Los Estados Partes se asegurarán de que en el derecho interno existan procedimientos aplicables a todas las formas de cooperación especificadas en la presente parte».

27 CÁRDENAS ARAVENA, Claudia. La cooperación de los Estados con la Corte Penal Internacional a la luz del Principio de Complementariedad. En: Revista de Derecho de la Pontificia Universidad Católica de Valparaíso, Valparaíso, Pontificia Universidad Católica de Valparaíso, 2010, pp. 281-304. P. 284. 
Por tanto, la colaboración le resulta esencial para investigar debidamente las comunicaciones y remisiones que recibe, reunir las pruebas para probar los cargos en juicio, dar cumplimiento a sus decisiones, ejecutar sus órdenes de detención, celebrar acuerdos, proteger a las víctimas y testigos, y obtener la inmunidad para que sus agentes desarrollen labores en terreno ${ }^{28}$.

Así, entonces, tanto el referido principio de complementariedad, como la estructura y funcionamiento con que fue concebida la Corte, explican la relevancia de la cooperación por parte de los Estados.

La concepción de cooperación incorporada al Estatuto de Roma, asociada al interés principal que respalda el accionar de la Corte, esto es la proscripción de toda forma de impunidad, constituye un régimen de cooperación mixta, diverso al régimen horizontal que existe entre los Estados, y al régimen vertical existente entre los Estados y los tribunales supranacionales en el que la obligación de cooperar es impuesta desde el Consejo de Seguridad de la ONU.

Esto significa que las obligaciones asociadas a la cooperación en el Estatuto presentan sanciones menos explícitas para los Estados que el régimen vertical, pero que su obligatoriedad va más allá del simple consenso de voluntades que originan las obligaciones de carácter horizontal; por tanto, si bien el Estatuto de Roma no contempla sanciones, sí contiene la obligación de carácter fáctico para los Estados de cooperar con la Corte Penal Internacional, artículos 86 y $\mathrm{Ss}^{29}{ }^{29}$, las que incluso involucran a los Estados no Partes en aquellas situaciones contempladas por el artículo 12(3) del Estatuto de Roma.

En concreto, y como consecuencia de este marco normativo, los Estados partes y sus autoridades deben garantizar que en su territorio la Corte pueda llevar a cabo una investigación efectiva, practicar allanamientos, localizar bienes, ubicar y proteger a víctimas y testigos, y detener y entregar a las personas acusadas. Para ello los países que no cuenten con disposiciones apropiadas deberán generar marcos normativos que se adecúen a los probables requerimientos de la Corte. En tal sentido, el artículo 88 del Estatuto consagra el deber de garantizar la existencia de procedimientos internos destinados a una cooperación eficiente.

En términos generales, dichos cuerpos normativos deberían consagrar procedimientos claros que permitan el diligenciamiento ágil y eficaz de cada acto de

28 ACUERDO SOBRE LOS PRIVILEGIOS E INMUNIDADES DE LA CORTE PENAL INTERNACIONAL. «Aprobado por la Asamblea de los Estados Partes en el Estatuto de la Corte Penal Internacional, en Nueva York, el 9 de septiembre de 2002».

29 CONTRERAS, Beatriz, Fernández, Karinna. Op. cit. p. 518. 
El principio de complementariedad en la investigación, juzgamiento y sanción de delitos internacionales

asistencia solicitado por el tribunal internacional. Un análisis comparado de las opciones desarrolladas por los Estados permite distinguir entre la adopción de tres tipos de instrumentos a saber: ${ }^{30}$

- Legislación especial relativa específicamente a la cooperación con la Corte e implementando los crímenes internacionales de genocidio, crímenes de lesa humanidad, crímenes de guerra.

- Legislación especial que introduce reformas a sus códigos penales y/o procesales penales, o incluso a sus disposiciones de rango constitucional.

- Cláusula genérica de remisión.

Conviene destacar que Colombia ratificó el Estatuto de Roma el 5 de agosto de 2002, y su implementación en el Código Penal colombiano fue adoptada incluso con anterioridad a la entrada en vigor del Estatuto de Roma. La ley procesal penal colombiana, en general, consagra diversos parámetros que rigen la cooperación judicial en materia penal, siendo parte bilateral y multilateral en diversos tratados ${ }^{31}$.

Específicamente, la cooperación con la Corte Penal Internacional de forma directa está regulada en el artículo 484 del Código Procesal Penal ${ }^{32}$, que estableciendo una cooperación ágil desde Colombia en respuesta a los principios de eficacia y economía de los procesos o solicitudes, estableciendo su implementación mediante las autoridades investigativas o judiciales, quienes podrán requerir u ofrecer la cooperación directamente ante las instancias correspondientes del tribunal internacional, mediante unos procedimientos que

30 GUERRERO, Humberto, Sirvent, María (coord.). Manual para la implementación del Estatuto de Roma en la legislación mexicana, 2008, pp. 35 y ss.

31 A modo de ejemplo: «Tratado de extradición con Brasil; Río de Janeiro, 28 de diciembre de 1938. fecha de entrada en vigor: 2 de octubre de 1940; la Convención de extradición de reos con Perú, tuvo como lugar y fecha de adopción la ciudad de Lima el 10 de febrero de 1870, y entró en vigor el día 13 de marzo de 1873; La convención de extradición de reos entre España y Colombia firmada en Bogotá el 21 de agosto de 1812 y aprobada mediante la Ley 32 de 1892; el Acuerdo de extradición de Caracas, del 18 de julio de 1911, que entró en vigor el 28 de julio de 1914; y el Convenio internacional para la represión de los actos terroristas cometidos con bombas, fue aprobado por el Congreso de la República de Colombia mediante la Ley 804 de 2003».

32 «Artículo 484: Principio General. Las autoridades investigativas y judiciales dispondrán lo pertinente para cumplir con los requerimientos de cooperación internacional que les sean solicitados de conformidad con la Constitución Política, los instrumentos internacionales y leyes que regulen la materia, en especial en desarrollo de la jurisdicción de la Corte Penal Internacional». 
contengan la información necesaria en conformidad con la legislación nacional y el Estatuto de Roma. Por su parte, la vía diplomática hace referencia al Ministerio de Relaciones Exteriores, organismo que podrá desarrollar ciertos trámites en su calidad de autoridad central, como una forma alternativa y complementaria para realizar las solicitudes de cooperación, mediante las notas suplicatorias ${ }^{33}$. Adicionalmente, corresponde mencionar que Colombia destaca entre el reducido número de países que ha suscrito un acuerdo sobre la ejecución de las penas impuestas por Corte Penal Internacional ${ }^{34}$.

\section{CONCLUSIONES}

De acuerdo con lo anterior, y como lo habíamos anunciado desde el comienzo, entre la jurisdicción de los Tribunales Nacionales, en la que se desarrolla tanto la jurisdicción nacional como la jurisdicción universal, y la jurisdicción de la Corte Penal Internacional, no existen tensiones, sino que estas se complementan.

Así, si la conducta punible se comete en un país, y en ese país se inicia la investigación, y al mismo tiempo en ese país procede la captura, ese país debe continuar el juzgamiento de tales conductas.

$\mathrm{Si}$, por el contrario, ese país donde se cometieron las conductas punibles no inicia la respectiva investigación, ni realiza las capturas, sino que la investigación la inicia otro país, y el mismo realiza las capturas, ese país, en virtud al principio de jurisdicción universal, debe realizar el juzgamiento.

En este caso, se debe precisar que si en el país donde se cometieron las conductas, se inicia la investigación, pero no se realizan las capturas, debe realizar los trámites de extradición ${ }^{35}$ respectiva, para que el capturado sea llevado al país donde cometió las conductas delictivas.

33 CASTILlO ECHEVERRY, Paola, Pino Girón, Diana. Estudio sobre Cooperación Internacional entre la Corte Penal Internacional y el Estado colombiano, Universidad de San Buenaventura, Cali, 2013, pp. 20-21.

34 Acuerdo entre la República de Colombia y la Corte Penal Internacional sobre la Ejecución de las Penas Impuestas por la Corte Penal Internacional, hecho en Bogotá D. C., el 17 de mayo de 2011.

35 «Principios de cooperación internacional en la identificación, detención, extradición y castigo de los culpables de crímenes de guerra, o de crímenes de lesa humanidad. Aprobados por la Asamblea General en su resolución 3074 (XXVIII), el 3 de diciembre de 1973. Artículo 11 Competencia temporal. 1. La Corte tendrá competencia únicamente respecto de crímenes cometidos después de la entrada en vigor del presente Estatuto. 2. Si un Estado se hace Parte en el presente Estatuto después de su entrada en 

juzgamiento y sanción de delitos internacionales

Y finalmente, si la persona es capturada en el país en donde cometió la conducta, o si la persona es capturada en otro país, y ninguno de estos quiere o puede adelantar el proceso de investigación y de juzgamiento, tal investigación, juzgamiento y sanción, una vez se verifique que se cumple con los requisitos exigidos para el efecto (competencia y admisibilidad), y de acuerdo con el principio de complementariedad, debe afrontarla la Corte Penal Internacional.

Luego es con base en este principio de complementariedad ${ }^{36}$, y en razón a que con posterioridad a la Segunda Guerra Mundial, el derecho penal y el procesal penal dejaron de ser locales para globalizarse ${ }^{37}, \mathrm{y}$ como quiera que se trata de conductas penales en las cuales la acción penal es imprescriptible ${ }^{38-40}$ que seña-

vigor, la Corte podrá' ejercer su competencia únicamente con respecto a los crímenes cometidos después de la entrada en vigor del presente Estatuto respecto de ese Estado, a menos que este haya hecho una declaración de conformidad con el párrafo 3 del artículo 12».

36 ESTATUTO DE LA CORTE PENAL INTERNACIONAL. «Adoptado por la Conferencia Diplomática de plenipotenciarios de las Naciones Unidas, Roma, el 17 de julio de 1998. Incisos $3 .^{\circ}$ y $4 .^{\circ}$ del Art. 93 de la Constitución Política de 1991, adicionados por el artículo 1. ${ }^{\circ}$ del Acto Legislativo nro. 2 de 2001 publicado en el Diario Oficial nro. 44.663, de 31 de diciembre de 2001. Artículo 1. ${ }^{\circ}$ - Se instituye por el presente una Corte Penal Internacional. La Corte será una institución permanente, estará facultada para ejercer su jurisdicción sobre personas respecto de los crímenes más graves de trascendencia internacional de conformidad con el presente Estatuto y tendrá carácter complementario de las jurisdicciones penales nacionales.»

37 PRINCIPIOS DE DERECHO INTERNACIONAL RECONOCIDOS POR EL ESTATUTO Y POR LAS SENTENCIAS DEL TRIBUNAL DE NUREMBERG. «Aprobados por la Comisión de Derecho Internacional de las Naciones Unidas en 1950. Principio II. El hecho de que el derecho interno no imponga pena alguna por un acto que constituya delito de derecho internacional no exime de responsabilidad en derecho internacional a quien lo haya cometido».

38 CONVENCIÓN SOBRE LA IMPRESCRIPTIBILIDAD DE LOS CRÍMENES DE GUERRA Y DE LOS CRÍMENES DE LESA HUMANIDAD. «Adoptada por la Asamblea General en su Resolución 2391 (XXIII), de 26 de noviembre de 1968. Entrada en vigor: 11 de noviembre de 1970».

39 Los Principios de Princeton sobre la Jurisdicción Universal. «Informe presentado al Secretario General de Naciones Unidas por la Misión Permanente del Canadá y la Misión Permanente del Reino de los Países Bajos ante las Naciones Unidas, aprobado por la Asamblea General de Naciones Unidas en su Resolución 56/677, de 4 de diciembre de 2001, durante su $56 .^{\circ}$ periodo de sesiones. Principio 6. Prescripción. Los delitos graves de derecho internacional que se enumeran en el párrafo 1 del Principio 2 son imprescriptibles».

40 ESTATUTO DE LA CORTE PENAL INTERNACIONAL. «Adoptado por la Conferencia Diplomática de plenipotenciarios de las Naciones Unidas, Roma, el 17 de julio de 1998. Incisos $3 .^{\circ}$ y $4 .^{\circ}$ del Art. 93 de la Constitución Política de 1991, adicionados por el artículo 1. ${ }^{\circ}$ del Acto Legislativo nro. 2 de 2001 publicado en el Diario Oficial nro. 44.663, de 31 de diciembre de 2001. Artículo 29. Imprescriptibilidad. Los crímenes de la competencia de la Corte no prescribirán». 
lamos que no existe tensión entre la jurisdicción nacional y la universal, y de estas con la de la Corte penal Internacional, sino que se complementan, para que tales conductas internacionales no queden en la impunidad.

\section{REFERENCIAS}

ACUERDO SOBRE LOS PRIVILEGIOS E INMUNIDADES DE LA CORTE PENAL INTERNACIONAL. Aprobado por la Asamblea de los Estados Partes en el Estatuto de la Corte Penal Internacional, en Nueva York, el 9 de septiembre de 2002.

ABOGADOSSIN FRONTERAS CANADÁ, CPI y Colombia: Tiempo de Actuar en positivo. En: Claudia Cárdenas y Karinna Fernández (eds.), La Corte Penal Internacional y sus primeros 10 años: Un enfoque práctico, Santiago de Chile, Thomson Reuters, 2013, pp. 319-359, p. 358. También en ABOGADOS SIN FRONTERAS CANADÁ (2012): «El principio de complementariedad en el Estatuto de Roma y la situación colombiana: más allá de lo positivo. Un análisis sobre la necesidad de adoptar otra aproximación frente a un Estado que no quiere judicializar los crímenes que comprometen su responsabilidad internacional y la de sus altos funcionarios». Disponible en: http:/ /www.asfcanada.ca/documents/file/asf_rapport-espagnol-v5_lq.pdf

CASSESE, Antonio, et al. Cassese's International Criminal Law. 3. ${ }^{\mathrm{a}}$ ed. Oxford: Oxford University Press, 2013.

CASTILLO ECHEVERRY, Paola, Pino Girón, Diana. Estudio sobre cooperación internacional entre la Corte Penal Internacional y el Estado colombiano, Universidad de San Buenaventura, Cali, 2013.

CONTRERAS, Beatriz, Fernández, Karinna. La obligación de cooperar con la Corte Penal Internacional. En: La Corte Penal Internacional y sus primeros 10 años: Un enfoque práctico, Santiago de Chile, Thomson Reuters, 2013, pp. 515-550, p. 518.

CONVENCIÓN SOBRE LA IMPRESCRIPTIBILIDAD DE LOS CRÍMENES DE GUERRA Y DE LOS CRÍMENES DE LESA HUMANIDAD. Adoptada por la Asamblea General en su Resolución 2391 (XXIII), de 26 de noviembre de 1968. Entrada en vigor: 11 de noviembre de 1970.

ESTATUTO DE LA CORTE PENAL INTERNACIONAL en el artículo $5 .^{\circ}$ los crímenes de genocidio, lesa humanidad, guerra y agresión. Adoptado por la Conferencia Diplomática de plenipotenciarios de las Naciones Unidas, Roma, el 17 de julio de 1998. Incisos 3. ${ }^{\circ}$ y $4 .^{\circ}$ del Art. 93 de la Constitución Política de 1991, adicionados por el artículo 1. ${ }^{\circ}$ del Acto Legislativo nro. 2 de 2001 publicado en el Diario Oficial nro. 44.663, de 31 de diciembre de 2001. 

juzgamiento y sanción de delitos internacionales

FEDERACIÓN INTERNACIONAL DE DERECHOS HUMANOS (FIDH), La CPI, 20022012: 10 años, 10 recomendaciones para una Corte Penal Internacional eficaz e independiente, París, 2012, p. 6.

GUERRERO, Humberto, Sirvent, María (coord.) Manual para la implementación del Estatuto de Roma en la legislación mexicana, 2008, pp. 35 y ss.

INFORME PRESENTADO AL SECRETARIO GENERAL DE NACIONES UNIDAS POR LA MISIÓN PERMANENTE DEL CANADÁ Y LA MISIÓN PERMANENTE DEL REINO DE LOS PAÍSES BAJOS ANTE LAS NACIONES UNIDAS, aprobado por la Asamblea General de Naciones Unidas en su Resolución 56/677, de 4 de diciembre de 2001, durante su $56 .^{\circ}$ periodo de sesiones.

JESSBERGER, Florian, Geneuss, Julia. Las múltiples caras de la Corte Penal Internacional. En: La Corte Penal Internacional y sus primeros 10 años: Un enfoque práctico, Santiago de Chile, Thomson Reuters, 2013, pp. 199-218, p. 207.

PRINCIPIOS DE DERECHO INTERNACIONAL RECONOCIDOS POR EL ESTATUTOY POR LAS SENTENCIAS DEL TRIBUNAL DE NUREMBERG. Aprobados por la Comisión de Derecho Internacional de las Naciones Unidas en 1950.

PRINCIPIOS DE COOPERACIÓN INTERNACIONAL EN LA IDENTIFICACIÓN, DETENCIÓN, EXTRADICIÓN Y CASTIGO DE LOS CULPABLES DE CRÍMENES DE GUERRA, O DE CRÍMENES DE LESA HUMANIDAD. Aprobados por la Asamblea General en su resolución 3074 (XXVIII), el 3 de diciembre de 1973.

SEGOVIA, Antonio, Contreras, Marcelo. El principio de complementariedad y el ejercicio de la competencia en el Estatuto de Roma. Una visión crítica. En: La Corte Penal Internacional y sus primeros 10 Años: Un enfoque práctico, Santiago de Chile, Thomson Reuters, 2013, pp. 265-302

VALDÉS RIVEROLL, Mariana. El Principio de complementariedad de la Corte Penal Internacional. En: Proyectos legislativos y otros temas penales (Segundas jornadas sobre justicia penal), México D. F.: Universidad Autónoma de México, 2003, pp. 293-299.

WERLE, Gerhard. El principio de complementariedad: una mirada retrospectiva y prospectiva. En: Corte Penal Internacional y jurisdicciones estatales. El principio de complementariedad, Santiago, Legal Publishing Chile, pp. 71-88. 